\title{
Knowledge Checking Service Selection Method in Pythagorean Fuzzy Environment
}

\author{
Ming Li \\ School of Business Administration \\ China University of petroleum \\ Beijing, China \\ brightliming@outlook.com \\ Yuqi Yu \\ School of Business Administration \\ China University of petroleum \\ Beijing, China \\ yyqxg2012@163.com
}

\author{
Yingcheng $\mathrm{Xu}$ \\ China National Institute of Standardization \\ Beijing, China \\ yingcheng_xu@126.com \\ * Corresponding Author
}

\begin{abstract}
Knowledge checking service is very important for safeguarding the quality of the knowledge in the knowledge repository. There are many knowledge checking services with similar functions but different qualities in organizations, especially in the crossing organizations. It is not easy to measure the non-functional criteria because of the complexity and the involvement of user's fuzzy perceptions of knowledge checking services. In order to help the evaluation and selection of the knowledge checking services, the knowledge checking services selection method in Pythagorean fuzzy environment is developed. Firstly, decision makers use linguistic terms to express their preferences on the alternative knowledge checking services with respect to each criterion. Afterwards, the linguistic terms are transformed into the Pythagorean fuzzy forms. Then the collective opinions are derived by aggregating the opinion given by each decision maker. After calculating the degree of linguistic grey relational coefficient of each alternative from PIS and NIS, the relative relational degree of each alternative from PIS are derived. Then all the alternatives are ranked in accordance with the relative relational degree in descending order. The illustrative example of knowledge service selection shows the proposed method is feasible and efficient.
\end{abstract}

Keywords- Knowledge Checking Service Selection; Multiple Attribute Group Decision Making; GRA; Pythagorean Fuzzy Sets

\section{INTRODUCTION}

In today's rapid changing environment, knowledge plays the important role in organizations $[1,2]$. It can keep and improve the core competition ability [3-5]. Since the knowledge within one organization is limited, more and more organizations try to build the alliance to use the knowledge outside the organizations [6-8]. The quality of knowledge in the knowledge repository determines the effects of knowledge sharing and using [9, 10]. Therefore, the knowledge needs to be checked before the using. The service oriented applications are developed and used more and more wildly. The level of knowledge checking service has great influence on the outcome of knowledge management. A knowledge checking service with superior quality can bring high value to organizations. In each organization, there are many knowledge checking services. These knowledge checking services may sometimes have the similar functions, especially in the alliance of many organizations. Measuring the quality of these services with similar functions but different qualities becomes an imperative concern for decision makers.

Therefore, these knowledge checking services with similar functions need to be evaluated and selected. In reality, the evaluation of knowledge checking services needs to be made from more than one aspect. With the increasing complexity, it is more and more difficult for single decision maker to give the accurate evaluation. In order to ease the bias of single decision maker and make the evaluation more accurate and objective, the evaluation should be made by more than one decision maker, which integrates various kinds of knowledge and experiences. Because of the complexity and the involvement of decision maker's fuzzy perceptions of knowledge checking services, in the evaluation of knowledge checking services, it is more and more difficult to derive or give precise numerical opinions. On the contrary, decision makers prefer to use the linguistic terms, which facilitates the expression of opinions.

Pythagorean fuzzy set (PFS) was proposed by Yager to model the linguistic terms [11-15]. The background of the PFSs is that in the decision making process, the sum of the support degree and the opposite degree to which an alternative with respect to one criterion provided by the decision maker may be bigger than one, but the sum of their squares is not more than one [12]. PFS is characterized by a membership degree and a nonmembership degree, which is similar to the intuitionistic fuzzy set [13-15]. The main differences between the Pythagorean fuzzy set and intuitionistic fuzzy set is that the square sum of PFS's membership degree and PFS's non-membership degree is not more than one, which can be deemed as the generalization of IFS. PFS release the restriction of the IFS and provides more loosing expression of fuzziness [16]. 
Grey relational analysis (GRA) is a commonly used tool to deal with the opinion given by a group of decision makers [17], which is an important part of grey system theory [18]. In grey system theory, the system with completely known information is called a white system; on the contrary, the system with completely unknown information is called a black system. If the information is partially known, the system is called a grey system [19, 20]. The calculation to deal with the opinions given by a group of decision makers based on GRA method is straightforward and the results are easier to be understood [21].

In this paper, a method for knowledge checking service selection method in Pythagorean fuzzy environment is developed. The remainder of this paper is organized as follows. In the next section, the Pythagorean fuzzy set is introduced. In the third Section, a method for knowledge checking service selection method in Pythagorean fuzzy environment is given. In the method, the opinions given by decision makers are expressed by the Pythagorean fuzzy sets. The GRA method is extended in the Pythagorean fuzzy environment to deal with the opinion given by a group of decision makers with respect to criteria. In Section 4, an illustrative example of knowledge service selection is given to verify the proposed approach. Finally, we conclude the paper.

\section{PRELIMINARIES}

Pythagorean fuzzy set (PFS) is characterized by membership degree and non-membership degree, the square sum of which is not more than one [11-15]. In the following, the definition and operators of Pythagorean fuzzy set is reviewed [16].

Let a set $X$ be a universe of discourse. The PFS $P$ can be represented as

$$
\begin{aligned}
P=\{ & <x, P\left(\mu_{P}(x), v_{P}(x)\right)> \\
& \left.\mid x \in X, 0 \leq\left(\mu_{P}(x)\right)^{2}+\left(v_{P}(x)\right)^{2} \leq 1\right\}
\end{aligned}
$$

Where, $\mu_{P}$ denotes the degree of membership, $v_{P}$ denotes the degree of non-membership of the element $x$ to $P$.

$P\left(\mu_{P}(x), v_{P}(x)\right)$ can be represent by $\beta=$ $P\left(\mu_{\beta}, v_{\beta}\right)$ simplicitly, where $\mu_{\beta}, v_{\beta} \in[0,1]$ and $\mu_{\beta}^{2}+$ $v_{\beta}^{2} \leq 1$.

Let $\beta_{j}=P\left(\mu_{\beta_{1}}, v_{\beta_{2}}\right)(j=1,2, \cdots, n)$ be the set of PFNs and $v=\left(v_{1}, v_{2}, \ldots, v_{m}\right)$ be the corresponding weight of $\beta_{j}(j=1,2, \cdots, m)$, where $0 \leq v_{j} \leq 1$ and $\sum_{i=1}^{m} v_{j}=1$, then the operators of the PFS can be defined as [16],

Definition 1 the sum of two PFNs can be defined as

$$
\beta_{1} \oplus \beta_{2}=P\left(\sqrt{\mu_{\beta_{1}}^{2}+\mu_{\beta_{2}}^{2}-\mu_{\beta_{1}}^{2} \mu_{\beta_{2}}^{2}}, v_{\beta_{1}} v_{\beta_{2}}\right)
$$

Definition 2 the product of two PFNs can be defined as

$$
\begin{aligned}
& \beta_{1} \otimes \beta_{2}=P\left(\mu_{\beta_{1}} \mu_{\beta_{2}}, \sqrt{v_{\beta_{1}}^{2}+v_{\beta_{2}}^{2}-v_{\beta_{1}}^{2} v_{\beta_{2}}^{2}}\right) \\
& \text { Definition } 3 \lambda \beta_{1}=P\left(\sqrt{1-\left(1-\mu_{\beta}^{2}\right)^{\lambda}}, v_{\beta}^{2}\right), \lambda> \\
& 0
\end{aligned}
$$

Definition 4 the distances between two PFNs can be defined as $\quad d\left(\beta_{1}, \beta_{2}\right)=\frac{1}{2}\left(\left|\left(\mu_{\beta_{1}}\right)^{2}-\left(\mu_{\beta_{2}}\right)^{2}\right|+\right.$ $\left|\left(v_{\beta_{1}}\right)^{2}-\left(v_{\beta_{2}}\right)^{2}\right|+\mid\left(\sqrt{1-\mu_{\beta_{1}}{ }^{2}-v_{\beta_{1}}{ }^{2}}\right)^{2}-$ $\left.\left(\left(\sqrt{1-\mu_{\beta_{2}}{ }^{2}-v_{\beta_{2}}{ }^{2}}\right)\right)^{2} \mid\right)$

Definition 6 The two PFNs can be compared by the following rules If $S\left(\beta_{1}\right)=S\left(\beta_{2}\right)$, then $\beta_{1} \sim \beta_{2}$

If $S\left(\beta_{1}\right)>S\left(\beta_{2}\right)$, then $\beta_{1} \prec \beta_{2}$

If $S\left(\beta_{1}\right)<S\left(\beta_{2}\right)$, then $\beta_{1}>\beta_{2}$

Where $S(\beta)=\mu_{\beta}{ }^{2}-v_{\beta}^{2}$.

Definition 7 The Pythagorean fuzzy weighted averaging operator (PFWAO) can be defiend as

$$
\operatorname{PFWAO}\left(\beta_{1}, \beta_{2}, \cdots, \beta_{m}\right)=P\left(\sum_{i=1}^{m} v_{\mathrm{i}} \mu_{\beta_{i}}, \sum_{i=1}^{m} v_{\mathrm{i}} \mu_{\beta_{i}}\right)
$$

\section{KNOWLEDGE CHECKING SERVICE SELECTION} METHOD IN PYTHAGOREAN FUZZY ENVIRONMENT

Let $A=\left\{A_{1}, A_{2}, \ldots, A_{m}\right\}$ be the set of alternatives, $D=\left\{D_{1}, D_{2}, \ldots, D_{t}\right\}$ be the set of decision makers, $C=\left\{C_{1}, C_{2}, \ldots, C_{n}\right\}$ be the set of criteria, $w=$ $\left(w_{1}, w_{2}, \ldots, w_{n}\right)$ be the weight vector of criteria, where $0 \leq w_{j} \leq 1$ and $\sum_{i=1}^{n} w_{j}=1$. Suppose $R=\left(r_{i j}^{k}\right)_{m \times n}$ is the group decision making matrix of the ratings to each alternative, where $r_{i j}^{k}$ is a preference values given by the decision maker $D_{k} \in D$.

To get the best knowledge checking service (s), by extending the GRA in Pythagorean fuzzy environment, the steps of the proposed method are given as follows:

Step1 Transforming linguistic decision matrix of the ratings to each alternative into Pythagorean fuzzy linguistic decision matrix.

Step2 Deriving the collective overall Pythagorean fuzzy linguistic decision matrix by aggregating the decision information given in matrix.

$$
\begin{aligned}
r_{i j}=\frac{1}{t} \sum_{k=1}^{t} r_{i j}^{k}= & P\left(\sum_{k=1}^{t} \frac{1}{t} \times u_{i j}^{k}, \frac{1}{t}\right. \\
& \left.\times \sum_{k=1}^{t} \frac{1}{t} \times v_{i j}^{k}\right)
\end{aligned}
$$

where $t$ is the number of decision makers.

Step3 Defining the positive ideal solution (PIS) and negative ideal solution (NIS) of the criteria as

$$
\begin{aligned}
& r^{+}=\left(r_{1}^{+}, r_{2}^{+}, \cdots, r_{n}^{+}\right) \\
& r^{-}=\left(r_{1}^{-}, r_{2}^{-}, \cdots, r_{n}^{-}\right)
\end{aligned}
$$

Where, the PIS and NIS of the criterion $C_{j}$ can be derived by

$$
\begin{aligned}
& r_{j}^{+}=\left\{r_{i j} \mid S\left(r_{i j}\right)=\max _{i}\left\{S\left(r_{i j}\right)\right\}\right\}, j=1,2, \cdots, n . \\
& r_{j}^{-}=\left\{r_{i j} \mid S\left(r_{i j}\right)=\min _{i}\left\{S\left(r_{i j}\right)\right\}\right\}, j=1,2, \cdots, n .
\end{aligned}
$$

Step4 Calculating the grey relational coefficient of each alternative from PIS and NIS.

Firstly, the distances of each alternative to PIS and NIS are defined as 


$$
\begin{aligned}
d_{i j}^{+}=d\left(r_{i j}, r_{j}^{+}\right)= & \frac{1}{2}\left(\left|\left(u_{i j}\right)^{2}-\left(u_{j}^{+}\right)^{2}\right|\right. \\
& +\left|\left(v_{i j}\right)^{2}-\left(v_{j}^{+}\right)^{2}\right| \\
& +\mid\left(1-\left(u_{i j}\right)^{2}-\left(v_{i j}\right)^{2}\right)-(1 \\
& \left.-\left(u_{j}^{+}\right)^{2}-\left(v_{j}^{+}\right)^{2} \mid\right) \\
d_{i j}^{-}=d\left(r_{i j}, r_{j}^{-}\right)= & \frac{1}{2}\left(\left|\left(u_{i j}\right)^{2}-\left(u_{j}^{-}\right)^{2}\right|\right. \\
& +\left|\left(v_{i j}\right)^{2}-\left(v_{j}^{-}\right)^{2}\right| \\
& +\mid\left(1-\left(u_{i j}\right)^{2}-\left(v_{i j}\right)^{2}\right)-(1 \\
& \left.-\left(u_{j}^{-}\right)^{2}-\left(v_{j}^{-}\right)^{2} \mid\right)
\end{aligned}
$$

Then grey relational coefficient of each alternative from PIS and NIS can be obtained by

$$
\begin{aligned}
\zeta_{i j}^{+} & =\frac{\min _{i} \min _{j} d_{i j}^{+}+\lambda \max _{i} \max _{j} d_{i j}^{+}}{d_{i j}^{+}+\lambda \max _{i} \max _{j} d_{i j}^{+}} \\
\zeta_{i j}^{-} & =\frac{\min _{i} \min _{j} d_{i j}^{-}+\lambda \max _{i} \max _{j} d_{i j}^{-}}{d_{i j}^{-}+\lambda \max _{i} \max _{j} d_{i j}^{-}}
\end{aligned}
$$

Where, $\lambda$ is the identification coefficient.

Step 5 Weighted grey relational coefficient of each alternative from PIS and NIS is derived by using the following equation, respectively:

$$
\begin{gathered}
\rho_{i}^{+}=\sum_{j=1}^{n} w_{j} \times \zeta_{i j}^{+}, i=1,2, \cdots, m \\
\rho_{i}^{-}=\sum_{j=1}^{n} w_{j} \times \zeta_{i j}^{-}, i=1,2, \cdots, m
\end{gathered}
$$

Step6. The relative relational degree of each alternative from PIS can be obtained by

$$
R C D_{i}=\frac{\rho_{i}^{+}}{\rho_{i}^{+}+\rho_{i}^{-}}, i=1,2,3, \cdots, m
$$

Then the alternatives can be ranked in the descending order according to the relative relational degrees.

\section{NUMERICAL EXAMPLE}

Suppose there are five knowledge checking services denoted by $A=\{A 1, A 2, A 3, A 4, A 5\}$ which have similar functions but different qualities are to be evaluated. In order to find the best knowledge checking service, five criteria are identified [22], which include 'Security' (C1), 'Transaction' (C2), 'Cost' (C3), 'Runtime' (C4) and 'Network' (C5). The weights of the criteria are $0.2,0.3$, $0.3,0.1$ and 0.1 . The decision makers denoted by $D=$ $\{D 1, D 2, D 3, D 4\}$ use the linguistic terms in Table 1 to express their preferences.
TABLE 1. LINGUISTIC TERMS

\begin{tabular}{|l|l|}
\hline Linguistic terms & PFNs \\
\hline Definitely low (DL) & {$[0.1,0.9]$} \\
\hline Very low (VL) & {$[0.2,0.8]$} \\
\hline Low (L) & {$[0.4,0.7]$} \\
\hline Medium (M) & {$[0.5,0.6]$} \\
\hline High (H) & {$[0.6,0.5]$} \\
\hline Very high (VH) & {$[0.7,0.3]$} \\
\hline Definitely high $(\mathrm{DH})$ & {$[0.9,0.1]$} \\
\hline
\end{tabular}

The linguistic rating of the five alternative knowledge checking services with respect to the five criteria given by the four decision makers are shown in Tables 2-5, respectively.

TABLE 2. RATINGS TO THE ALTERNATIVES AND WEIGHT OF CRITERIA GIVEN BY D1

\begin{tabular}{|l|l|l|l|l|l|}
\hline & C1 & C2 & C3 & C4 & C5 \\
\hline A1 & DL & VL & H & M & DH \\
\hline A2 & DH & L & DL & DH & L \\
\hline A3 & DL & DH & DH & DH & VH \\
\hline A4 & DH & DL & DH & H & H \\
\hline A5 & L & DH & L & DL & VH \\
\hline
\end{tabular}

TABLE 3. RATINGS TO THE ALTERNATIVES AND WEIGHT OF CRITERIA GIVEN BY D2

\begin{tabular}{|l|l|l|l|l|l|}
\hline & C1 & C2 & C3 & C4 & C5 \\
\hline A1 & H & H & VH & M & H \\
\hline A2 & DL & L & DL & M & DH \\
\hline A3 & DH & DH & M & H & VH \\
\hline A4 & H & DL & H & DL & DL \\
\hline A5 & L & DH & M & H & L \\
\hline
\end{tabular}

TABLE 4. RATINGS TO THE ALTERNATIVES AND WEIGHT OF CRITERIA

\begin{tabular}{|l|l|l|l|l|l|}
\hline & C1 & C2 & C3 & C4 & C5 \\
\hline A1 & H & H & VH & VH & VH \\
\hline A2 & DL & H & L & H & VL \\
\hline A3 & H & VH & DH & H & DL \\
\hline A4 & VH & VL & H & DL & L \\
\hline A5 & M & H & DH & H & DH \\
\hline
\end{tabular}

TABLE 5. RATINGS TO THE ALTERNATIVES AND WEIGHT OF CRITERIA GIVEN BY D4

\begin{tabular}{|l|l|l|l|l|l|}
\hline & C1 & C2 & C3 & C4 & C5 \\
\hline A1 & VH & M & L & VL & DH \\
\hline A2 & M & DL & M & DL & H \\
\hline A3 & DL & M & DH & M & L \\
\hline A4 & L & L & M & VL & VL \\
\hline A5 & M & VL & VH & M & H \\
\hline
\end{tabular}

In the following, the proposed approach is used to rank the alternative(s):

Step1 Transforming linguistic ratings in Tables 2-5 into Pythagorean fuzzy linguistic forms, which are shown in Table 6-9, respectively.

TABLE 6. TRANSFORMED RATINGS TO THE ALTERNATIVES GIVEN BY D1

\begin{tabular}{|c|c|c|c|c|c|}
\hline & $\mathrm{C} 1$ & $\mathrm{C} 2$ & $\mathrm{C} 3$ & $\mathrm{C} 4$ & $\mathrm{C} 5$ \\
\hline A1 & $\mathrm{P}(0.2,0.9)$ & $\mathrm{P}(0.3,0.8)$ & $\mathrm{P}(0.6,0.5)$ & $\mathrm{P}(0.5,0.6)$ & $\mathrm{P}(0.9,0.2)$ \\
\hline A2 & $\mathrm{P}(0.9,0.2)$ & $\mathrm{P}(0.4,0.7)$ & $\mathrm{P}(0.2,0.9)$ & $\mathrm{P}(0.9,0.2)$ & $\mathrm{P}(0.4,0.7)$ \\
\hline A3 & $\mathrm{P}(0.2,0.9)$ & $\mathrm{P}(0.9,0.2)$ & $\mathrm{P}(0.9,0.2)$ & $\mathrm{P}(0.9,0.2)$ & $\mathrm{P}(0.7,0.4)$ \\
\hline A4 & $\mathrm{P}(0.9,0.2)$ & $\mathrm{P}(0.2,0.9)$ & $\mathrm{P}(0.9,0.2)$ & $\mathrm{P}(0.6,0.5)$ & $\mathrm{P}(0.6,0.5)$ \\
\hline A5 & $\mathrm{P}(0.4,0.7)$ & $\mathrm{P}(0.9,0.2)$ & $\mathrm{P}(0.4,0.7)$ & $\mathrm{P}(0.2,0.9)$ & $\mathrm{P}(0.7,0.4)$ \\
\hline
\end{tabular}


TABLE 7. TRANSFORMED RATINGS TO THE ALTERNATIVES GIVEN BY D2

\begin{tabular}{|c|c|c|c|c|c|}
\hline & C1 & C2 & C3 & C4 & C5 \\
\hline A1 & $\mathrm{P}(0.6,0.5)$ & $\mathrm{P}(0.6,0.5)$ & $\mathrm{P}(0.7,0.4)$ & $\mathrm{P}(0.5,0.6)$ & $\mathrm{P}(0.6,0.5)$ \\
\hline A2 & $\mathrm{P}(0.2,0.9)$ & $\mathrm{P}(0.4,0.7)$ & $\mathrm{P}(0.2,0.9)$ & $\mathrm{P}(0.5,0.6)$ & $\mathrm{P}(0.9,0.2)$ \\
\hline A3 & $\mathrm{P}(0.9,0.2)$ & $\mathrm{P}(0.9,0.2)$ & $\mathrm{P}(0.5,0.6)$ & $\mathrm{P}(0.6,0.5)$ & $\mathrm{P}(0.7,0.4)$ \\
\hline A4 & $\mathrm{P}(0.6,0.5)$ & $\mathrm{P}(0.2,0.9)$ & $\mathrm{P}(0.6,0.5)$ & $\mathrm{P}(0.2,0.9)$ & $\mathrm{P}(0.2,0.9)$ \\
\hline A5 & $\mathrm{P}(0.4,0.7)$ & $\mathrm{P}(0.9,0.2)$ & $\mathrm{P}(0.5,0.6)$ & $\mathrm{P}(0.6,0.5)$ & $\mathrm{P}(0.4,0.7)$ \\
\hline
\end{tabular}

TABLE 8. TRANSFORMED RATINGS TO THE ALTERNATIVES GIVEN BY D3

\begin{tabular}{|c|c|c|c|c|c|}
\hline & C1 & C2 & C3 & C4 & C5 \\
\hline A1 & $\mathrm{P}(0.6,0.5)$ & $\mathrm{P}(0.6,0.5)$ & $\mathrm{P}(0.7,0.4)$ & $\mathrm{P}(0.7,0.4)$ & $\mathrm{P}(0.7,0.4)$ \\
\hline A2 & $\mathrm{P}(0.2,0.9)$ & $\mathrm{P}(0.6,0.5)$ & $\mathrm{P}(0.4,0.7)$ & $\mathrm{P}(0.6,0.5)$ & $\mathrm{P}(0.3,0.8)$ \\
\hline A3 & $\mathrm{P}(0.6,0.5)$ & $\mathrm{P}(0.7,0.4)$ & $\mathrm{P}(0.9,0.2)$ & $\mathrm{P}(0.6,0.5)$ & $\mathrm{P}(0.2,0.9)$ \\
\hline A4 & $\mathrm{P}(0.7,0.4)$ & $\mathrm{P}(0.3,0.8)$ & $\mathrm{P}(0.6,0.5)$ & $\mathrm{P}(0.2,0.9)$ & $\mathrm{P}(0.4,0.7)$ \\
\hline A5 & $\mathrm{P}(0.5,0.6)$ & $\mathrm{P}(0.6,0.5)$ & $\mathrm{P}(0.9,0.2)$ & $\mathrm{P}(0.6,0.5)$ & $\mathrm{P}(0.9,0.2)$ \\
\hline
\end{tabular}

TABLE 9. TRANSFORMED RATINGS TO THE ALTERNATIVES GIVEN BY D4

\begin{tabular}{|c|c|c|c|c|c|}
\hline & C1 & C2 & C3 & C4 & C5 \\
\hline A1 & $\mathrm{P}(0.7,0.4)$ & $\mathrm{P}(0.5,0.6)$ & $\mathrm{P}(0.4,0.7)$ & $\mathrm{P}(0.3,0.8)$ & $\mathrm{P}(0.9,0.2)$ \\
\hline A2 & $\mathrm{P}(0.5,0.6)$ & $\mathrm{P}(0.2,0.9)$ & $\mathrm{P}(0.5,0.6)$ & $\mathrm{P}(0.2,0.9)$ & $\mathrm{P}(0.6,0.5)$ \\
\hline A3 & $\mathrm{P}(0.2,0.9)$ & $\mathrm{P}(0.5,0.6)$ & $\mathrm{P}(0.9,0.2)$ & $\mathrm{P}(0.5,0.6)$ & $\mathrm{P}(0.4,0.7)$ \\
\hline A4 & $\mathrm{P}(0.4,0.7)$ & $\mathrm{P}(0.4,0.7)$ & $\mathrm{P}(0.5,0.6)$ & $\mathrm{P}(0.3,0.8)$ & $\mathrm{P}(0.3,0.8)$ \\
\hline A5 & $\mathrm{P}(0.5,0.6)$ & $\mathrm{P}(0.3,0.8)$ & $\mathrm{P}(0.7,0.4)$ & $\mathrm{P}(0.5,0.6)$ & $\mathrm{P}(0.6,0.5)$ \\
\hline
\end{tabular}

Step 2 Utilizing the decision information given in Table 6-9 to derive the collective overall Pythagorean fuzzy linguistic decision information, the results of which are shown in Table 10.

TABLE 10. AGGREgATED RATINGS TO THE ALTERNATIVES AND WEIGHT TO EACH CRITERIA

\begin{tabular}{|c|c|c|c|c|c|}
\hline & C1 & C2 & C3 & C4 & C5 \\
\hline \multirow{2}{*}{ A1 } & $\begin{array}{c}\mathrm{P}(0.525,0 \\
.575)\end{array}$ & $\mathrm{P}(0.5,0.6)$ & $\mathrm{P}(0.6,0.5)$ & $\mathrm{P}(0.5,0.6)$ & $\mathrm{P}(0.775,0$ \\
& & $325)$ \\
\hline \multirow{2}{*}{ A2 } & $\begin{array}{c}\mathrm{P}(0.45,0 . \\
65)\end{array}$ & $\mathrm{P}(0.4,0.7)$ & $\mathrm{P}(0.325,0$ & $\mathrm{P}(0.55,0$. & $\mathrm{P}(0.55,0$. \\
& $.775)$ & $55)$ & $55)$ \\
\hline \multirow{2}{*}{ A3 } & $\begin{array}{c}\mathrm{P}(0.475,0 \\
.625)\end{array}$ & $\begin{array}{c}\mathrm{P}(0.75,0 . \\
35)\end{array}$ & $\mathrm{P}(0.8,0.3)$ & $\begin{array}{c}\mathrm{P}(0.65,0 . \\
45)\end{array}$ & $\mathrm{P}(0.5,0.6)$ \\
\hline \multirow{2}{*}{ A4 } & $\begin{array}{c}\mathrm{P}(0.65,0 . \\
45)\end{array}$ & $\begin{array}{c}\mathrm{P}(0.275,0 \\
.825)\end{array}$ & $\begin{array}{c}\mathrm{P}(0.65,0 . \\
45)\end{array}$ & $\begin{array}{c}\mathrm{P}(0.325,0 \\
.775)\end{array}$ & $\begin{array}{c}\mathrm{P}(0.375,0 \\
.725)\end{array}$ \\
\hline \multirow{2}{*}{ A5 } & $\begin{array}{c}\mathrm{P}(0.45,0 . \\
65)\end{array}$ & $\begin{array}{c}\mathrm{P}(0.675,0 \\
.425)\end{array}$ & $\begin{array}{c}\mathrm{P}(0.625,0 \\
.475)\end{array}$ & $\begin{array}{c}\mathrm{P}(0.475,0 \\
.625)\end{array}$ & $\begin{array}{c}\mathrm{P}(0.65,0 . \\
45)\end{array}$ \\
\hline
\end{tabular}

Step3 Defining the PIS and NIS

The $S$ function is used to compare the aggregated rating values. The value of $S$ function of each alternative with respect to the criteria is shown in Table 11.

TABLE 11. Values of S function

\begin{tabular}{|l|l|l|l|l|l|}
\hline & C1 & C2 & C3 & C4 & C5 \\
\hline A1 & -0.055 & -0.11 & 0.11 & -0.11 & 0.495 \\
\hline $\mathbf{A 2}$ & -0.22 & -0.33 & -0.495 & 0 & 0 \\
\hline $\mathbf{A 3}$ & -0.165 & 0.44 & 0.55 & 0.22 & -0.11 \\
\hline $\mathbf{A 4}$ & 0.22 & -0.605 & 0.22 & -0.495 & -0.385 \\
\hline $\mathbf{A 5}$ & -0.22 & 0.275 & 0.165 & -0.165 & 0.22 \\
\hline
\end{tabular}

Then with (9), the PIS and NIS of each criteria can be found, which are shown in Table 12.
TABLE 12. PIS AND NIS

\begin{tabular}{|c|c|c|c|c|c|}
\hline & C1 & C2 & C3 & C4 & C5 \\
\hline PI & $\mathrm{P}(0.65,0.7$ & $\mathrm{P}(0.75,0.7$ & $\mathrm{P}(0.8,0.65$ & $\mathrm{P}(0.65,0.7)$ & $\begin{array}{c}\mathrm{P}(0.45,0.6 \\
5)\end{array}$ \\
$\mathrm{S}$ & $5)$ & ) & ) & & $\mathrm{P}(0.325,0$. \\
\hline $\begin{array}{c}\text { NI } \\
\mathrm{S}\end{array}$ & $\mathrm{P}(0.45,0.7$ & $\mathrm{P}(0.275,0$. & $\mathrm{P}(0.325,0$. & $\mathrm{P}(0.3,0.8)$ \\
\hline
\end{tabular}

Step4 Calculating the grey relational coefficient of each alternative from PIS and NIS

With (10) and (11), the distances of each alternative with respect to each criterion from PIS and NIS are obtained, which are shown in Table 13 and 14, respectively.

TABLE 13. DISTANCES OF EACH ALTERNATIVE FROM PIS

\begin{tabular}{|c|c|c|c|c|c|}
\hline & C1 & C2 & C3 & C4 & C5 \\
\hline A1 & 0.379 & 0.443 & 0.453 & 0.303 & 0.398 \\
\hline A2 & 0.360 & 0.403 & 0.534 & 0.308 & 0.120 \\
\hline A3 & 0.369 & 0.368 & 0.333 & 0.288 & 0.062 \\
\hline A4 & 0.360 & 0.487 & 0.438 & 0.317 & 0.103 \\
\hline A5 & 0.360 & 0.416 & 0.446 & 0.296 & 0.220 \\
\hline
\end{tabular}

TABLE 14. DISTANCES OF EACH ALTERNATIVE FROM NIS

\begin{tabular}{|c|c|c|c|c|c|}
\hline & C1 & C2 & C3 & C4 & C5 \\
\hline A1 & 0.159 & 0.284 & 0.464 & 0.202 & 0.534 \\
\hline A2 & 0.067 & 0.324 & 0.561 & 0.197 & 0.338 \\
\hline A3 & 0.099 & 0.487 & 0.584 & 0.317 & 0.280 \\
\hline A4 & 0.288 & 0.431 & 0.479 & 0.298 & 0.114 \\
\hline A5 & 0.067 & 0.380 & 0.471 & 0.208 & 0.438 \\
\hline
\end{tabular}

By using (12) and (13), the grey relational coefficient of each alternative from PIS and NIS can be obtained, which are shown in Table 15 and 16, respectively.

TABLE 15. GREY RELATIONAL COEFFICIENT OF EACH ALTERNATIVE FROM PIS

\begin{tabular}{|c|c|c|c|c|c|}
\hline & C1 & C2 & C3 & C4 & C5 \\
\hline A1 & 0.486 & 0.444 & 0.438 & 0.548 & 0.472 \\
\hline A2 & 0.500 & 0.469 & 0.394 & 0.544 & 0.791 \\
\hline A3 & 0.493 & 0.494 & 0.522 & 0.562 & 0.919 \\
\hline A4 & 0.500 & 0.418 & 0.447 & 0.535 & 0.825 \\
\hline A5 & 0.500 & 0.460 & 0.441 & 0.554 & 0.636 \\
\hline
\end{tabular}

TABLE 16. GREY RELATIONAL COEFFICIENT OF EACH ALTERNATIVE FROM NIS

\begin{tabular}{|c|c|c|c|c|c|}
\hline & $\mathbf{C 1}$ & $\mathbf{C 2}$ & $\mathbf{C 3}$ & $\mathbf{C 4}$ & $\mathbf{C 5}$ \\
\hline $\mathbf{A 1}$ & 0.722 & 0.565 & 0.431 & 0.660 & 0.394 \\
\hline $\mathbf{A 2}$ & 0.906 & 0.529 & 0.382 & 0.666 & 0.518 \\
\hline $\mathbf{A 3}$ & 0.832 & 0.418 & 0.372 & 0.535 & 0.570 \\
\hline $\mathbf{A 4}$ & 0.562 & 0.451 & 0.422 & 0.552 & 0.802 \\
\hline $\mathbf{A 5}$ & 0.906 & 0.485 & 0.427 & 0.651 & 0.447 \\
\hline
\end{tabular}

Step 5 Calculating weighted grey relational coefficient of each alternative from PIS and NIS.

By using (14) and (15), firstly, the weighted grey relational coefficient of each alternative with respect to each criteria from PIS and NIS can be obtained, which are shown in Table $17-18$, respectively. Then the grey relational coefficient of each alternative from PIS and NIS can be derived, which is shown in Table 19. 
TABLE 17. WEIGHTED GREY RELATIONAL COEFFICIENT OF EACH ALTERNATIVE WITH RESPECT TO EACH CRITERIA FROM PIS

\begin{tabular}{|c|c|c|c|c|c|}
\hline & C1 & C2 & C3 & C4 & C5 \\
\hline A1 & 0.097 & 0.133 & 0.131 & 0.055 & 0.047 \\
\hline A2 & 0.100 & 0.141 & 0.118 & 0.054 & 0.079 \\
\hline A3 & 0.099 & 0.148 & 0.157 & 0.056 & 0.092 \\
\hline A4 & 0.100 & 0.126 & 0.134 & 0.054 & 0.082 \\
\hline A5 & 0.100 & 0.138 & 0.132 & 0.055 & 0.064 \\
\hline
\end{tabular}

TABLE 18. WEIGHTED GREY RELATIONAL COEFFICIENT OF EACH ALTERNATIVE WITH RESPECT TO EACH CRITERIA FROM NIS

\begin{tabular}{|c|c|c|c|c|c|}
\hline & C1 & C2 & C3 & C4 & C5 \\
\hline A1 & 0.144 & 0.170 & 0.129 & 0.066 & 0.039 \\
\hline A2 & 0.181 & 0.159 & 0.115 & 0.067 & 0.052 \\
\hline A3 & 0.166 & 0.126 & 0.112 & 0.054 & 0.057 \\
\hline A4 & 0.112 & 0.135 & 0.127 & 0.055 & 0.080 \\
\hline A5 & 0.181 & 0.145 & 0.128 & 0.065 & 0.045 \\
\hline
\end{tabular}

TABLE 19. GREY RELATIONAL COEFFICIENT OF EACH ALTERNATIVE FROM PIS AND NIS

\begin{tabular}{|l|l|l|l|l|l|}
\hline & A1 & A2 & A3 & A4 & A5 \\
\hline PIS & 0.464 & 0.492 & 0.552 & 0.495 & 0.489 \\
\hline NIS & 0.549 & 0.573 & 0.514 & 0.510 & 0.565 \\
\hline
\end{tabular}

Step 6 Calculating the relative closeness degree of each alternative from PIS.

The relative relational degrees of each alternative are derived by (16), the results of which are shown in Table 20 .

TABLE 20. RELATIVE RELATIONAL DEGREES

\begin{tabular}{|l|l|l|l|l|}
\hline A1 & A2 & A3 & A4 & A5 \\
\hline 0.458 & 0.462 & 0.518 & 0.493 & 0.464 \\
\hline
\end{tabular}

Then the alternatives can be ranked in the descending order according to the relative relational degrees and the ranking is: $A 3>A 4>A 5>A 2>A 1$.

\section{CONCLUSION}

This paper proposed the method for the evaluation and selection of the knowledge checking services. In the method, the linguistic terms are provided to decision makers to express their opinions on the alternatives with respect to more than one criterion. Then the opinions which are in the form of linguistic terms are transformed into the Pythagorean fuzzy forms. After the aggregation of opinion of each user, the collective opinions are derived. Then based on the idea of GRA, the relative relational degrees of each alternative from PIS are derived. All the alternatives are ranked in accordance with the relative relational degree in the descending order. The alternative that has the highest relative relational degree is the best knowledge checking service. The illustrative example of knowledge service selection shows the proposed method is feasible and efficient. With the method, when facing many knowledge checking services with similar functions but different qualities, the best knowledge checking service can be find more objectively and accurately.

\section{ACKNOWLEDGMENT}

The research is supported by the National Natural Science Foundation of China under Grant No. 71101153, 71301152, and Science Foundation of China University of Petroleum, Beijing (No. 2462015YQ0722), Humanity and Social Science Youth Foundation of Ministry of Education in China (No. 13YJC790112)

\section{REFERENCES}

[1] Rubenstein-Montano, Bonnie, et al. "A systems thinking framework for knowledge management." Decision support systems 31.1 (2001): 5-16.

[2] Zheng, Wei, Baiyin Yang, and Gary N. McLean. "Linking organizational culture, structure, strategy, and organizational effectiveness: Mediating role of knowledge management." Journal of Business Research 63.7 (2010): 763-771.

[3] Wang, Sheng, Raymond A. Noe, and Zhong-Ming Wang. "Motivating Knowledge Sharing in Knowledge Management Systems A Quasi-Field Experiment." Journal of Management 40.4 (2014): 978-1009.

[4] Alavi, Maryam, and Dorothy E. Leidner. "Review: Knowledge management and knowledge management systems: Conceptual foundations and research issues." MIS quarterly (2001): 107-136.

[5] Wiig, Karl M. "Knowledge management: where did it come from and where will it go?." Expert systems with applications 13.1 (1997): 1-14

[6] Jermol, Mitja, Nada Lavrac, and Tanja Urbancic. "Managing business intelligence in a virtual enterprise: a case study and knowledge management lessons learned." Journal of Intelligent \& Fuzzy Systems: Applications in Engineering and Technology 14.3 (2003): 121-136.

[7] Carayannopoulos, Sofy, and Ellen R. Auster. "External knowledge sourcing in biotechnology through acquisition versus alliance: A KBV approach." Research Policy 39.2 (2010): 254-267.

[8] Zhang, Haisu, et al. "Managing knowledge for innovation: the role of cooperation, competition, and alliance nationality." Journal of International Marketing 18.4 (2010): 74-94.

[9] Star, Jon R., and Gabriel J. Stylianides. "Procedural and conceptual knowledge: exploring the gap between knowledge type and knowledge quality." Canadian Journal of Science, Mathematics and Technology Education 13.2 (2013): 169-181.

[10] Kane, Aimée A., Linda Argote, and John M. Levine. "Knowledge transfer between groups via personnel rotation: Effects of social identity and knowledge quality." Organizational behavior and human decision processes 96.1 (2005): 56-71.

[11] Yager, R. R. (2014). Pythagorean membership grades in multicriteria decision making. Fuzzy Systems, IEEE Transactions on, 22(4), 958-965.

[12] Yager, Ronald R. "Pythagorean fuzzy subsets." IFSA World Congress and NAFIPS Annual Meeting (IFSA/NAFIPS), 2013 Joint. IEEE, 2013.

[13] Yager, R. R., \& Abbasov, A. M. (2013). Pythagorean membership grades, complex numbers, and decision making. International Journal of Intelligent Systems, 28(5), 436-452.

[14] Yager, Ronald R., and Ali M. Abbasov. "Pythagorean membership grades, complex numbers, and decision making." International Journal of Intelligent Systems 28.5 (2013): 436-452.

[15] Yager, Ronald R. "Pythagorean membership grades in multicriteria decision making." Fuzzy Systems, IEEE Transactions on 22.4 (2014): 958-965.

[16] Zhang, Xiaolu, and Zeshui Xu. "Extension of TOPSIS to multiple criteria decision making with pythagorean fuzzy sets." International Journal of Intelligent Systems 29.12 (2014): 1061-1078.

[17] Salardini, Firoozeh. "An AHP-GRA method for asset allocation: a case study of investment firms on Tehran Stock Exchange." Decision Science Letters 2.4 (2013): 275-280.

[18] Deng, Ju-Long. "Introduction to grey system theory." The Journal of grey system 1.1 (1989): 1-24.

[19] Lu, Meng, and Kees Wevers. "Grey system theory and applications: a way forward." Journal of Grey System 10.1 (2007) 47-53.

[20] Tseng, Ming-Lang. "Using linguistic preferences and grey 
relational analysis to evaluate the environmental knowledge management capacity." Expert systems with applications 37.1 (2010): 70-81.

[21] Zhang, Shi-fang, San-yang Liu, and Ren-he Zhai. "An extended GRA method for MCDM with interval-valued triangular fuzzy assessments and unknown weights." Computers \& Industrial
Engineering 61.4 (2011): 1336-1341.

[22] Wang, Ping. "QoS-aware web services selection with intuitionistic fuzzy set under consumer's vague perception." Expert Systems with Applications 36.3 (2009): 4460-4466. 